\title{
Re: Comments on "Reduction malarplasty combined with facelift via the prezygomatic space"
}

\author{
Yoon Joo Lee ${ }^{1}$, Il Seok Lee ${ }^{2}$, Ho Jik Yang ${ }^{2}$ \\ ${ }^{1}$ Doctorsmi Aesthetic Plastic Surgical Clinic, Daejeon; ${ }^{2}$ Department of Plastic and Reconstructive Surgery, Eulji University Hospital, Daejeon, Korea
}

This is a response to comments on our paper recently published in Arch Aesthetic Plast Surg (Lee et al. Reduction malarplasty combined with facelift via the prezygomatic space) [1].

The main distinctive feature of this paper is that reduction malarplasty was done through the facelift incision alone. In general, reduction malarplasty is performed via an intraoral approach. However, when we performed surgery using the facelift technique, the prezygomatic space was accessible, allowing us to adequately perform reduction malarplasty.

As mentioned by the commenter, the procedure may seem similar to the method described in a recent paper [2]. However, the author of the previous paper [2] performed malar reduction through an oral incision, and then an additional skin incision was made for the facelift. Our procedure is different in that reduction malarplasty can be performed simultaneously with the facelift via the same incision. This method can reduce the oral infection rate and discomfort of the patient.

In conclusion, our study showed that bony contouring can be done in an efficient way while performing a facelift.

\section{NOTES}

Conflict of interest

No potential conflict of interest relevant to this article was reported.

ORCID

Yoon Joo Lee

Il Seok Lee

Ho Jik Yang

https://orcid.org/0000-0003-4915-8282 https://orcid.org/0000-0002-8313-2513 https://orcid.org/0000-0003-0839-780X

\section{REFERENCES}

1. Lee YJ, Lee IS, Yang HJ. Reduction malarplasty combined with facelift via the prezygomatic space. Arch Aesthetic Plast Surg 2020;26:138-43.

2. Zhou J, Qi Z, Jin X. Simultaneous surgery for contouring the prominent zygoma and mandibular angles with facelift in middle-aged patients. J Craniofac Surg 2020;31:448-52.

Received: Jun 21, 2021 Revised: Jun 22, 2021 Accepted: Jun 28, 2021

Correspondence: Ho Jik Yang Department of Plastic and Reconstructive Surgery, Eulji University Hospital, 95 Dunsanseo-ro, Seo-gu, Daejeon 35233, Korea Tel: +82-42-611-3029, Fax: +82-42-259-1111, E-mail: drhjyang@eulji.ac.kr 